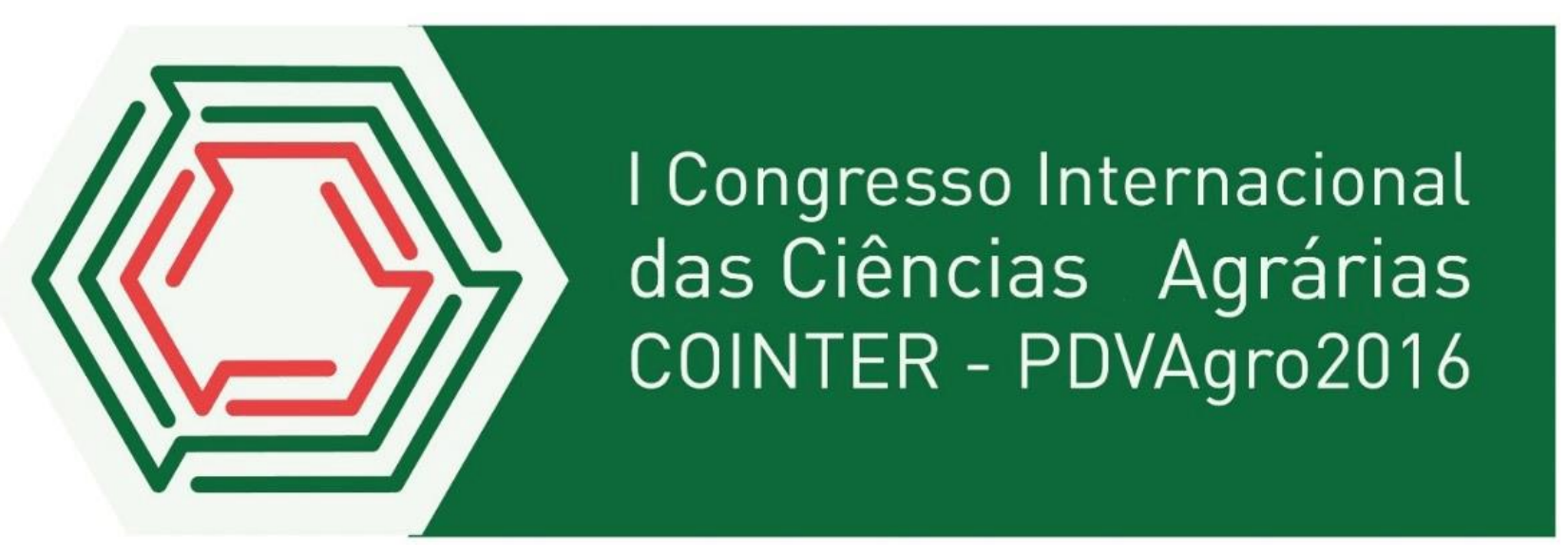

\title{
ORIENTAÇÕES SANITÁRIAS AOS CAPRINOVINOCULTORES DO ASSENTAMENTO POÇO E CARVÃO EM SÃO LOURENÇO DA MATA/PE
}

Apresentação: Relato de Experiência

Lucas Leandro da Silva Soares ${ }^{1}$; Taylane Alves da Silva²; Maria Islane Araújo Ferreira ${ }^{3}$; Manoel Aleixo Batista Neto ${ }^{4}$, Ellen Cordeiro Bento da Silva ${ }^{5}$

\section{Introdução}

Falhas no manejo sanitário na criação de pequenos ruminantes configuram-se como um fator limitante e que gera perdas significativas nos rebanhos (Oliveira, 2008). Muitos desses pequenos criadores iniciam a produção com baixa ou nenhuma qualificação e/ou experiência na criação desses animais e consequente noções básicas no manejo sanitário, reprodutivo e nutricional (Coelho et al, 2011). Isso influência diretamente a produção, com animais portadores de doenças infectocontagiosas, trazendo consigo prejuízos financeiros devido a gastos com medicamentos e alta mortalidade (Filgueira et al, 2009). Dessa forma objetivou-se demonstrar as atividades de capacitação realizadas pela a equipe de extensão no Assentamento Poço e Carvão.

\section{Relato de Experiência}

Foram realizadas visitas técnicas em pequenas propriedades rurais do Assentamento Poço e Carvão, no município de São Lourenço da Mata/PE, onde ofertou-se a campo e na sede da associação do assentamento capacitações por meio de palestras expositiva proferidas por docente e discentes de Medicina Veterinária e Zootecnia, vinculados ao projeto "Conscientização e capacitação de caprinovinocultores para o uso da fisiologia como uma ferramenta na adoção de boas práticas nas criações".

\footnotetext{
${ }^{1}$ Medicina Veterinária, Universidade Federal Rural de Pernambuco (UFRPE), lucasleandrovet@gmail.com

${ }^{2}$ Medicina Veterinária, Universidade Federal Rural de Pernambuco (UFRPE), taylaneallves@hotmail.com

${ }^{3}$ Medicina Veterinária, Universidade Federal Rural de Pernambuco (UFRPE), laninha756@gmail.com

${ }^{4}$ Medicina Veterinária, Universidade Federal Rural de Pernambuco (UFRPE), manoelaleixo96@hotmail.com

${ }^{5}$ Docente, Phd, Universidade Federal Rural de Pernambuco (UFRPE), silva.ecb@gmail.com
} 
Nas propriedades visitadas, durante o período de maio a agosto de 2016, foram atendidos caprinos e ovinos, onde foram realizadas juntamente com a participação dos criadores, orientações referentes ao manejo sanitário dos animais, onde foram demonstrados a realização de alguns procedimentos, como exame das mucosas, através do método FAMACHA, desverminação, cura do umbigo em borregos e cabritos, e avaliações gerais dos animais acometidos com outras enfermidades. Outras temáticas também foram abordadas durante as palestras realizadas, como seleção de reprodutores e reprodutoras, manejo da fêmea gestante, cuidados com a cria. Os proprietários também foram orientados sobre a necessidade da limpeza das instalações e o descarte adequado das fezes, evitando dessa forma uma reinfecção parasitária, foi abordado a importância da realização quarentena dos animais recém-adquiridos, bem como o isolamento e/ou descarte dos animais doentes.

Imagem 1: Atividades realizadas durante o projeto. Fonte: Própria
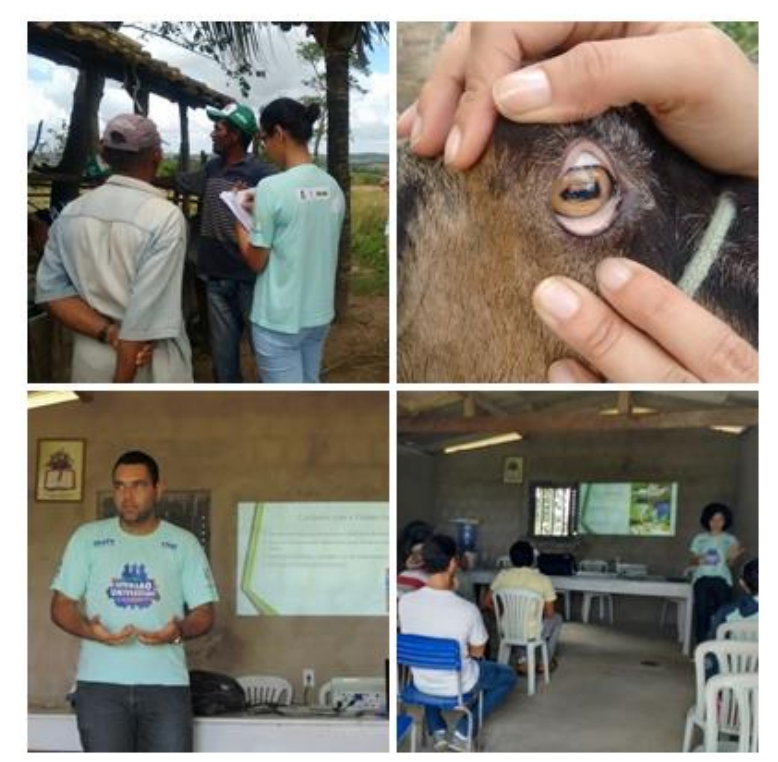

\section{Considerações}

Dessa forma, nota-se que é de suma que as atividades de capacitação sejam realizadas, por meio das atividades de Extensão Rural, promovendo a qualificação dos pequenos produtores visando potencializar as atividades pecuárias da região.

\section{Referências}

COELHO M. C. S. C.; SOUZA V. C.; COELHO M. I. S.; CUNHA M. P.; MEDINA F. T.; Aspectos sanitários de rebanhos caprinos e ovinos criados em assentamentos no município de Petrolina- 
PE. Revista Semiárido De Visu, v.1, n.1, p. 32-40, 2011.

FILGUEIRA T. M. B.; AHID S. M. M.; SUASSUNA A. C. D.; SOUZA W. J.; FONSECA Z. A. A. S.; Aspectos epidemiológicos e sanitários das criações de caprinos na região da Chapada do Apodi. Revista Verde (Mossoró - RN - Brasil) v.4, n.2, p. 64 - 67 abril/junho de 2009.

OLIVEIRA, E. D. Manejo sanitário de pequenos ruminantes. Sobral: Embrapa Caprinos e Ovinos, 2008. 